\title{
Escapando da Atmosfera com Galaxy Escape
}

\author{
Thomas G. de Brito ${ }^{1}$, Gilvandenys L. Sales ${ }^{1}$, Francisco L. P. Lourenço ${ }^{1}$, Luiz H. A. \\ Santos ${ }^{1}$ \\ ${ }^{1}$ Oficina de Ciências, Arte e Tecnologia (CIARTEC) \\ Instituto Federal do Ceará (IFCE) - Fortaleza, CE - Brasil \\ \{thomasce10,johnson.peixotoo, henriqueanjos12\} @gmail.com, \\ denyssalesdifce.edu.br
}

\begin{abstract}
Resumo. $O$ recente tema sobre viagens espaciais e o interesse por parte de iniciativas privadas, que possuem interesse em turismo espacial, tem sido notícia na mídia, por isso necessita de mais alfabetização científica. Posto isto, este trabalho apresenta o OA Galaxy Escape com propósito de esclarecer lançamentos de foguetes para o público da Educação Básica na disciplina de Física. Foi tomado o referencial conceitual de velocidade de escape e órbita para embasar o software com o objetivo de auxiliar o aluno a entender $e$ diferenciar quando um corpo lançado pode orbitar ou escapar da gravidade do planeta. Espera-se dos alunos a aprendizagem significativa dos conceitos do $O A$.
\end{abstract}

\section{Cenário de Uso}

Desde os PCNs+ (BRASIL, 2002) às atuais discussões acerca das reformulações curriculares pautadas na atual BNCC (Base Nacional Comum Curricular) que se enfatiza um ensino de ciência e o desenvolvimento tecnológico contemporâneo.

Tais $\mathrm{PCNs}+$ propõem temas estruturadores para organizar o Ensino de Física em habilidades e competências, são eles: Movimentos: variações e conservações; Calor, ambiente e usos de energia; Som, imagem e informação; Equipamentos elétricos e telecomunicações; Matéria e Radiação e aquele relacionado ao Cosmo: Universo, Terra e Vida.

O tema Universo, Terra e Vida são orientadas para uma compreensão de natureza cosmológica da Terra, do Sistema Solar e a origem e evolução do Universo. Preocupa-se com os modelos explicativos do universo e sua evolução, desde as partículas elementares às estrelas e galáxias, passando pelos tipos de forças de interação que agem na constituição da matéria. Este tema tenta responder os enigmas da vida e do universo: De onde viemos? Para onde vamos? Como se formaram os planetas e os corpos celestes em geral? E suas atmosferas? Somos realmente filhos das estrelas? Questionamentos frequentes nas mentes de nossos jovens.

O conteúdo pedagógico digital que se propõe neste trabalho, representado pelo Galaxy Escape pretende esclarecer os conceitos de velocidade de escape de um planeta, afinal é tema bastante discutido na atualidade tanto pela NASA quanto pela Tesla que pretende lançar viagens espaciais para Marte.

Por consequência do tema e pelo crescente interesse por parte de crianças e jovens em relação ao espaço e a astronomia, o OA tem como público-alvo alunos da educação básica na disciplina de Física. 
VII Congresso Brasileiro de Informática na Educação (CBIE 2018)

Anais dos Workshops do VII Congresso Brasileiro de Informática na Educação (WCBIE 2018)

\section{Desenvolvimento}

Adotou-se como metodologia de desenvolvimentos de objeto de aprendizagem (OA) as fases propostas por Sales (2012) (Figura 1).

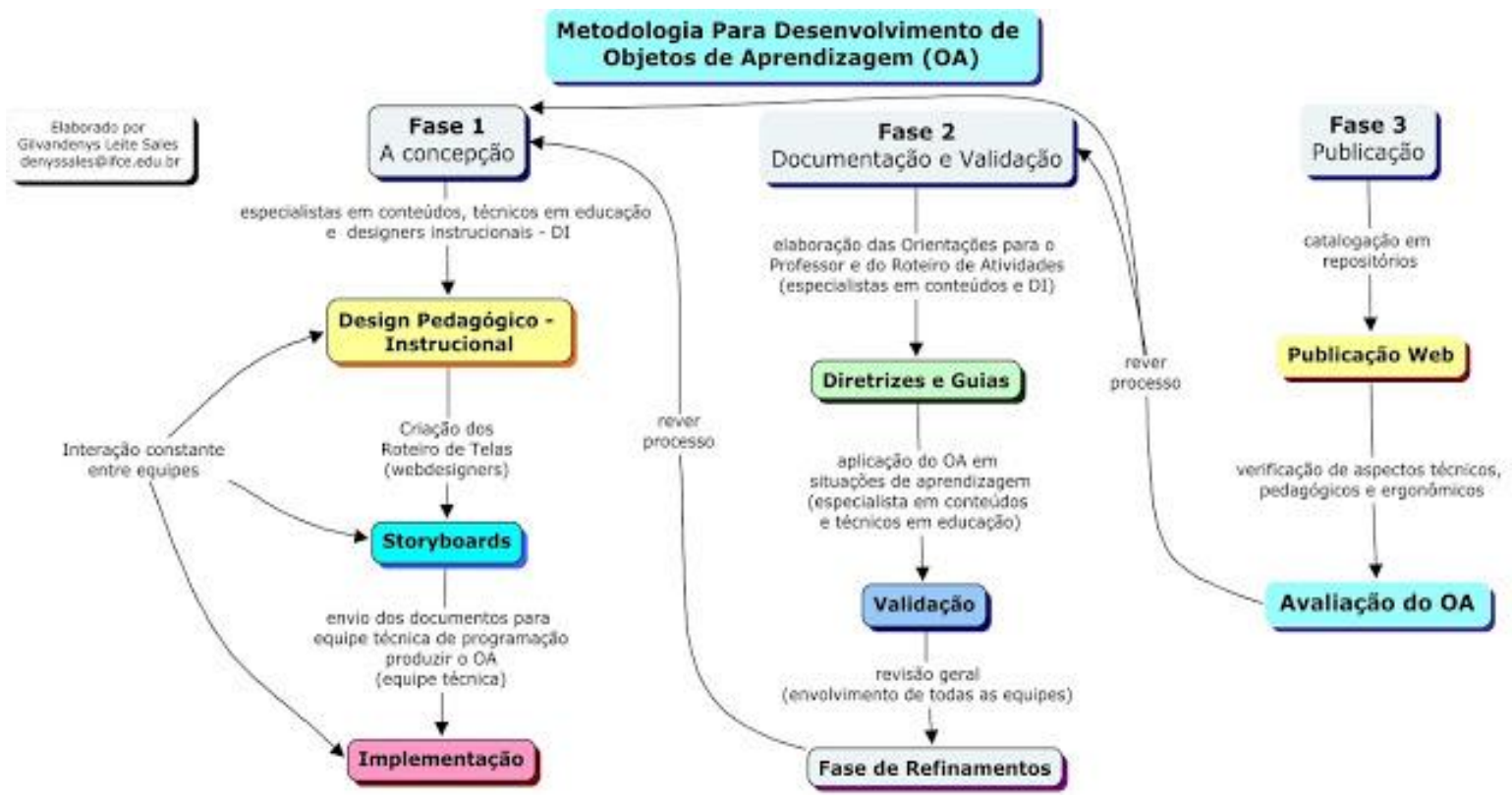

Figura 1. Metodologia de desenvolvimento de AO

Fonte: Sales (2012)

Este trabalho apresenta a Fase 1 da proposta de Sales (2012), em que se concebeu o OA e criaram-se os roteiros de tela.

De início, é realizada uma reflexão de como o aluno irá interagir com o Objeto de Aprendizagem planejado, e sua relação com o quotidiano, sem escapar dos conceitos abordados do OA.

A relação entre o cotidiano e os temas abordados no OA pode resguardar a interação ambicionada pelo professor, justamente por estes fatores construir o OA possuindo estas características potencializa sua interação [Santos 2017].

O objetivo, o tema que o OA deseja explorar, a metodologia, e os elementos a serem tratados dentro do objeto são elaborados nesta concepção.

Posteriormente com a ideia finalizada, inicia-se a etapa de concepção do storyboard, onde os responsáveis pela criação da interface de usuário criam e concebem as telas do OA, esta etapa interage com o design pedagógico na fase de criação. Nesta fase as ideias ganham contornos baseados no que fora proposto inicialmente.

O objeto de Aprendizagem Galaxy Escape está sendo desenvolvido utilizando o software Cocos Creator que utiliza um framework open-source e permite publicação em HTML5, Android e IOS.

$\mathrm{Na}$ fase inicial foi utilizado o software Animate $\mathrm{CC}$, que possui ferramentas para criar animações, gráficos vetorizados, scripts e permite um aumento considerável na eficiência de criação de protótipos e, por fim, possibilitando o desenvolvimento ágil do aplicativo final, porém foi preterido em favor do Cocos Creator devido ao fato de não possuir suporte a Android e IOS. 
VII Congresso Brasileiro de Informática na Educação (CBIE 2018)

Anais dos Workshops do VII Congresso Brasileiro de Informática na Educação (WCBIE 2018)

Devido ao fato de ter sido desenvolvido em HTML5 e Android a linguagem de programação Javascript é obrigatória para o desenvolvimento do OA.

Para gerenciamento de projeto está sendo utilizado o Trello.

Para controle de versão e colaboração da equipe foi escolhido o GitHub.

Para conceitualização e criação de gráficos vetorizados está sendo utilizado o Adobe Illustrator.

Sua validação, por ainda estar em fase de prototipagem, e possuir alguns conceitos, tais como: elementos de games e de mídia que ainda não foram implementadas, deverá ser posteriormente realizada.

\section{Apresentação do Software}

Apresentam-se nesta seção os storyboards do OA. Como está em fase de protótipo as telas estão sujeitas a mudanças, como por exemplo, a adição de mais animações.

\subsection{Apresenta-se a tela de abertura (Figura 2)}

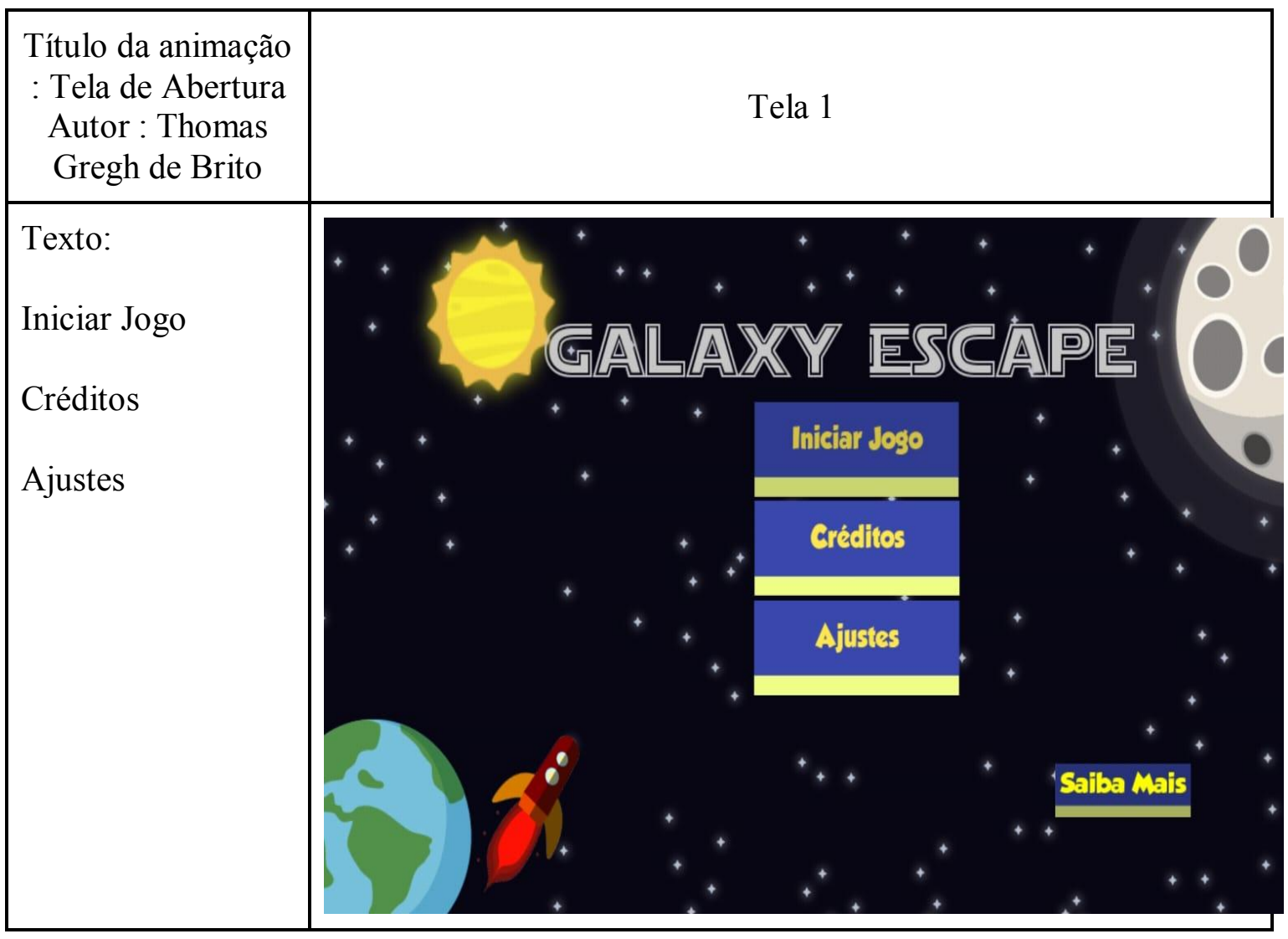

Figura 2. Tela 1 Tela de Abertura

Fonte: Próprio autor

Explicação sobre a Ação: O aluno ao clicar no botão "Iniciar Jogo" que está no centro da tela abre uma outra tela dentro de um planeta com um foguete na base de lançamento. O aluno ao clicar no botão "Créditos" será mostrado informações sobre os 
VII Congresso Brasileiro de Informática na Educação (CBIE 2018)

Anais dos Workshops do VII Congresso Brasileiro de Informática na Educação (WCBIE 2018)

desenvolvedores do $\mathrm{OA}$ e ao clicar em Ajustes poderá habilitar o modo de acessibiilidade e ajustar os sons do App.

A seguir a tela de créditos com informações sobre a equipe de desenvolvimento.

\subsection{Tela de Créditos (Figura 3)}

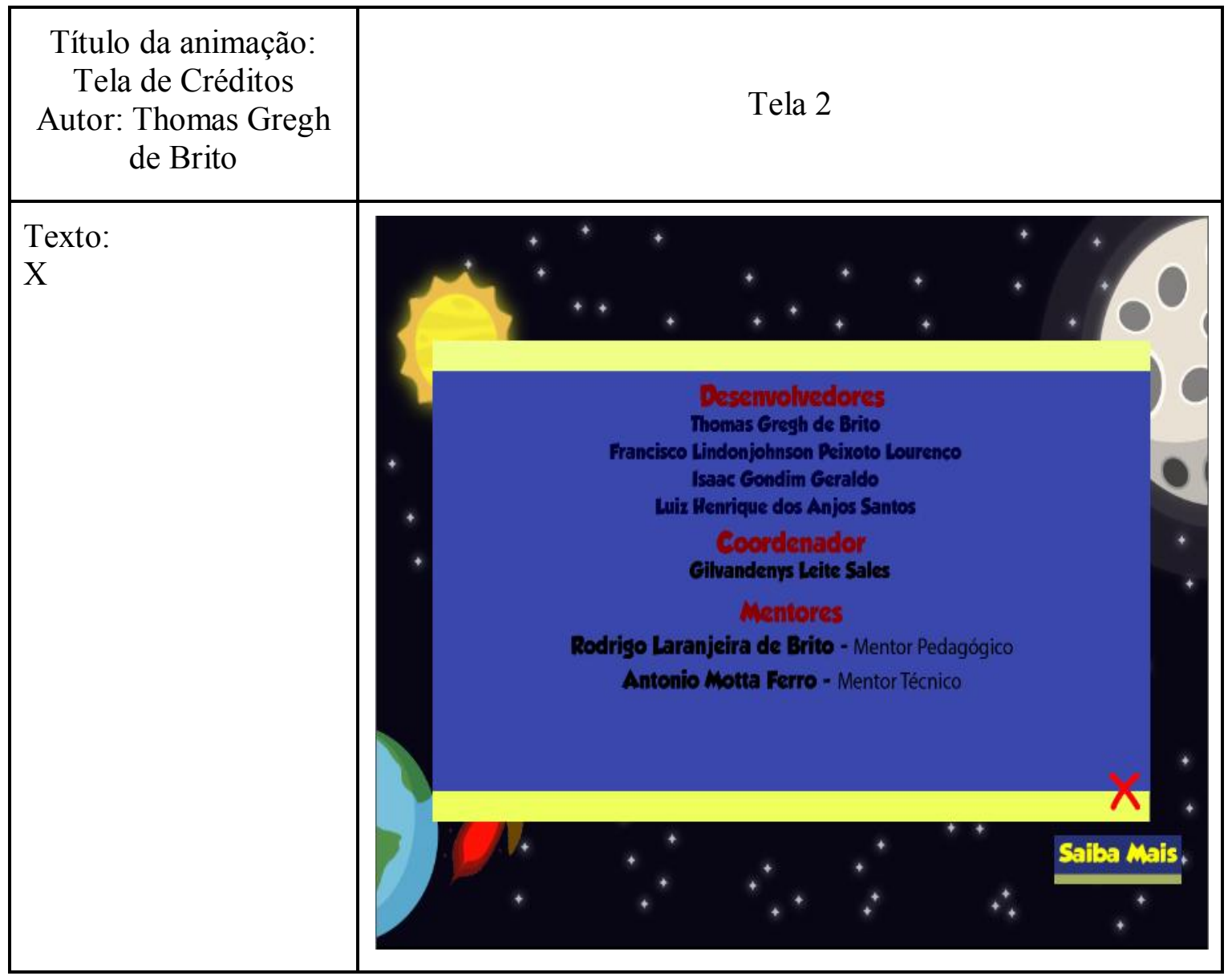

Figura 3. Tela 2 Tela de Créditos

Fonte: Próprio autor

Explicação sobre a Ação:

- O aluno ao clicar no botão "X" que fica no canto inferior direito o aluno fechará a aba de créditos (Tela 1).

- Após isso ao cliclar no botão "Iniciar Jogo" (Tela 1) mostra-se a tela de planetas. 
VII Congresso Brasileiro de Informática na Educação (CBIE 2018)

Anais dos Workshops do VII Congresso Brasileiro de Informática na Educação (WCBIE 2018)

\subsection{Tela de Planetas (Figura 4)}

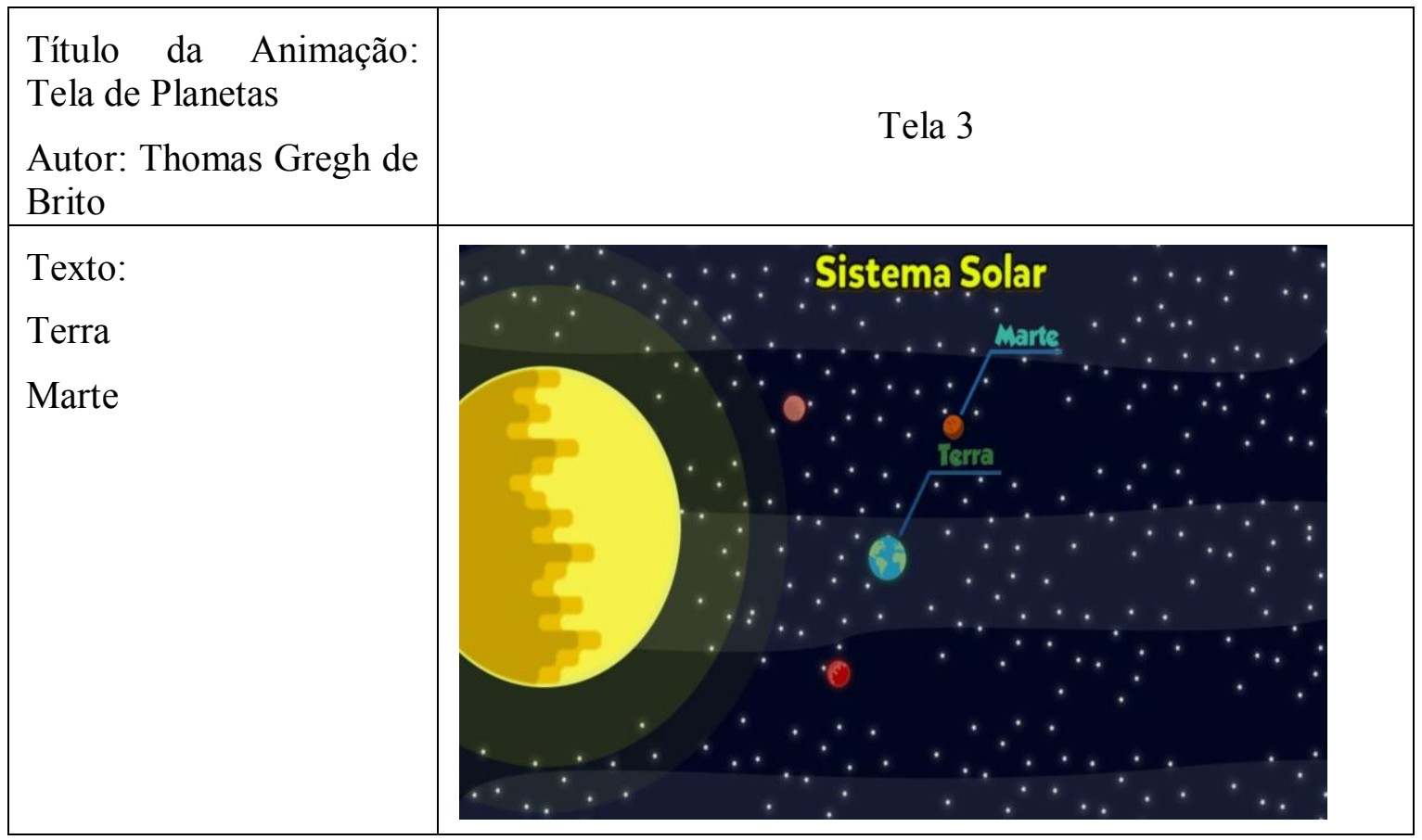

Figura 4. Tela 3 Tela de Seleção de Planetas

Fonte: Próprio autor

Explicação sobre a Ação:

- Terra : Irá para a Tela de Lançamento do Planeta Terra

- Marte : Irá para a Tela de Lançamento do Planeta Marte

\subsection{Tela de Lançamento (Figura 5)}

Título da Animação: Tela de Simulação

Tela 4

Autor: Thomas Gregh de Brito 
VII Congresso Brasileiro de Informática na Educação (CBIE 2018)

Anais dos Workshops do VII Congresso Brasileiro de Informática na Educação (WCBIE 2018)

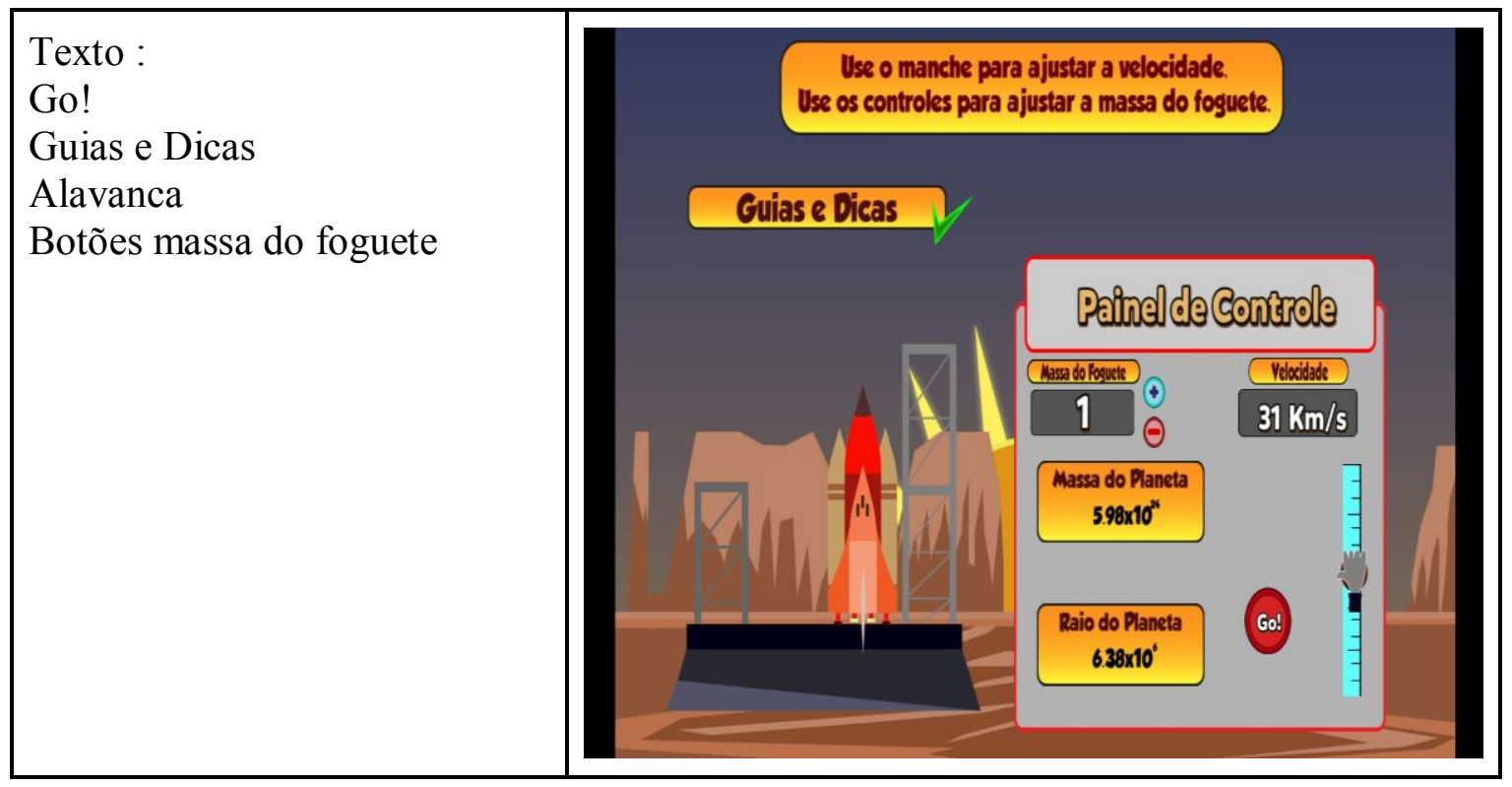

Figura 5. Tela 4 Tela de Simulação

Fonte: Próprio autor

Explicação sobre a Ação:

- Go! : O foguete é lançado

- Guias e Dicas: Fornece instruções para o aluno sobre o significado dos botões e fornece informações adicionais sobre a Atividade e os controles, além de guias para o aluno e professor e materiais de suporte.

- Alavanca: Permite ao Aluno escolher a Velocidade do Foguete.

- Botões de massa do foguete: Aumentam ou Diminuem a massa do foguete agindo como um multiplicador.

E por fim a tela de resultados. 
VII Congresso Brasileiro de Informática na Educação (CBIE 2018)

Anais dos Workshops do VII Congresso Brasileiro de Informática na Educação (WCBIE 2018)

\subsection{Tela de Resultados (Figura 6)}

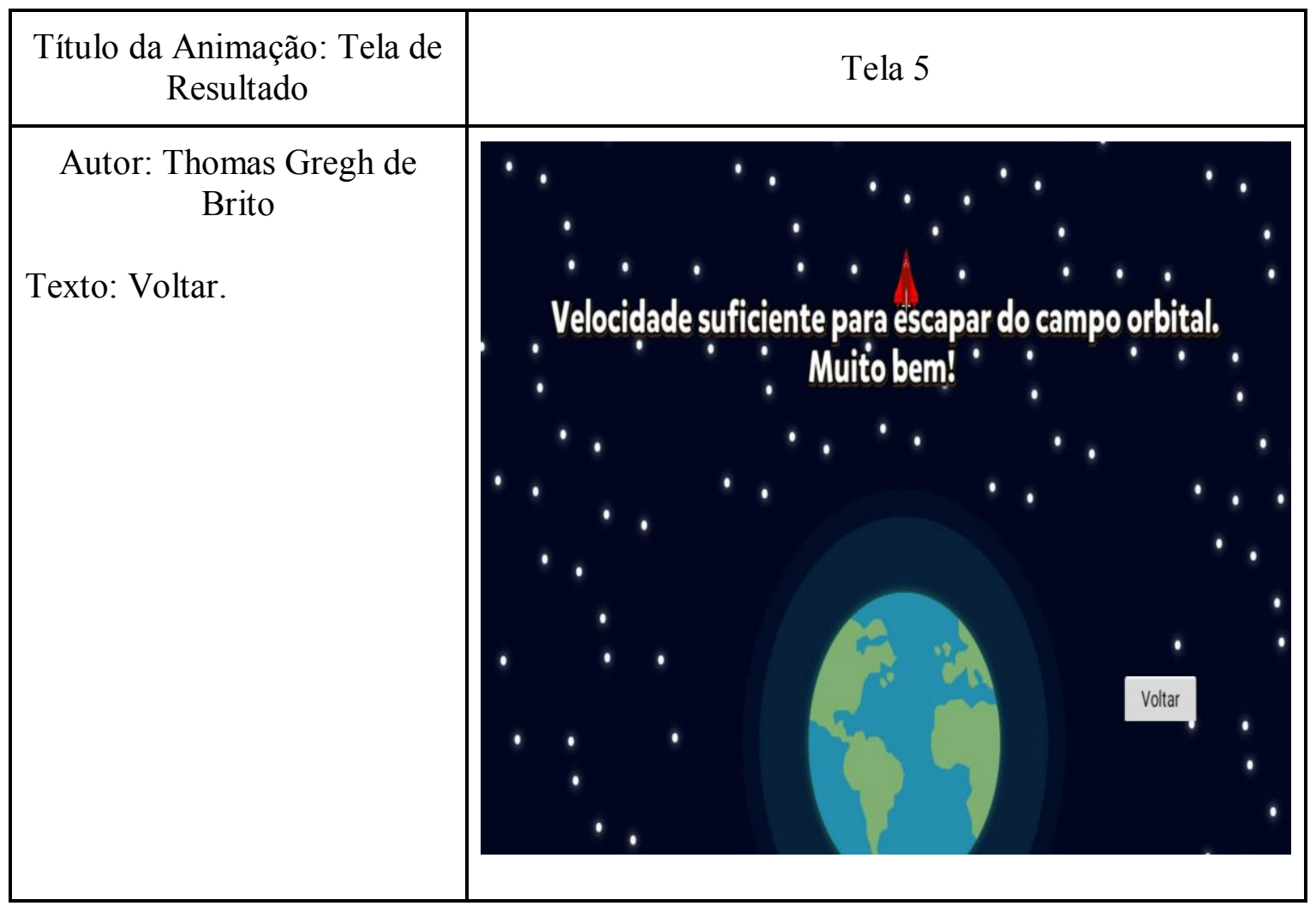

Figura 6. Tela 5 Tela de Resultado

Fonte: Próprio autor

Explicação sobre a Ação:

Nesta tela se o Aluno usou combustível demais se inserir uma velocidade muito acima da velocidade de escape da atmosfera o OA retornará uma mensagem alertando-o sobre isso e exibirá a animação do foguete saindo da atmosfera.

Para Cada Planeta haverá uma tela com feedback para:

- Caso a velocidade do foguete for inferior a de escape e maior que a de órbita será exibida uma animação do foguete orbitando o planeta.

- Caso o Aluno tenha inserido uma velocidade acima porém próxima a de escape será exibido uma mensagem de parabenização e a animação do foguete saindo da atmosfera: "Parabéns, seu lançamento foi um sucesso!".

Caso a velocidade não seja nem a de escape, nem a de órbita surge a mensagem:

- "Relançar foguete! Velocidade muito baixa o Foguete retornará à Base de lançamento".

O OA está sob licença do tipo Creative Commons CC BY 4.0 e poderá ser aplicado em sala de aula através de projetores, smartphones e PC's. 
VII Congresso Brasileiro de Informática na Educação (CBIE 2018)

Anais dos Workshops do VII Congresso Brasileiro de Informática na Educação (WCBIE 2018)

\section{Considerações finais}

O software facilitará a compreensão por parte do aluno sobre os fenônemos relacionados ao lançamento de foguetes e velocidade de escape, por se tratar de um OA gamificado permite uma aprendizagem significativa dos conceitos abordados ao mesmo tempo que auxilia o professor a construir um espaço motivador dentro da sala de aula.

Para tanto, é necessária a criação de roteiros de atividades para que o aluno possa explorar o OA de forma individual ou em grupo fazendo valer uma aprendizagem colaborativa.

Por fim, espera-se que este OA contribua para auxiliar os professores no ensino de Física e que isto possa despertar nos alunos o crescente interesse pela Física, como também que compreendam melhor os fenômenos no seu entorno, e assim, possam relacionar teoria e prática.

Destaca-se para trabalhos futuros a atualização constante do OA, sua validação, captação e monitoramento das informações fornecidas pelos usuários para criação de um banco de dados para pesquisa.

\section{Referências}

Brasil (2002). Secretaria da Educação Média e Tecnológica. PCN+: Ensino Médio orientações educacionais complementares aos Parâmetros Curriculares Nacionais. Brasília: MEC.

Sales, G. L. (2012). Como Fazer um OA? Uma metodologia para desenvolver Objetos de Aprendizagem. Disponível em: https://goo.gl/H6P5Se Acesso em: 25 jun. 2018.

Santos, R. L. dos. (2017). Aplicação de uma metodologia envolvendo mudanças conceituais no ensino de Física moderna e contemporânea. 2017. Dissertação (PósGraduado em Ensino de Ciências e Matemática). - Instituto Federal do Ceará. Fortaleza/Ceará. 